Journal of Environmental Sciences (JES)

Institute of Environmental Studies and Research, Ain Shams University

El-Leithy, et al.

\title{
DEVELOPING AN INNOVATIVE TECHNIQUE TO ENABLE ESTIMATE OF SURFACE AREA OF ASWAN HIGH DAM LAKE USING SATELLITE IMAGES
}

\author{
Belal M. El-Leithy ${ }^{(1)}$; Aly El Bahrawy ${ }^{(2)}$; Noha Samir Donia ${ }^{(3)}$ \\ and Ayman Nasr Hamed Nasr ${ }^{(4)}$
}

1) Post Grade, Institute of Environmental Studies and Research, Ain Shams University 2) Faculty of Engineering, Ain shams University 3) Institute of Environmental Studies and Research, Ain Shams University 4) National Authority for Remote Sensing and space Sciences

\begin{abstract}
Water scarcity in Egypt requires better management of water resources. The most important parameters needed for lake water management are the lake surface area and volume at any specific time. This study focused on developing an innovative technique that enables the accurate calculation of the lake surface area at any specific time using satellite images. Neal-real time and long-term water body monitoring is essential for the effective management and conservation of Lake Nasser as one of the most important water resources in Egypt, which is enormously benefited from the advent of remotely sensed images. However, an efficient as well as robust method to perform water detection from these images remains challenging due to the various noise sources from heterogeneous backgrounds. A robust methodology is designed in this study to extract free surface water from multi-temporal and multispectral images acquired by Landsat-8 Operational Land Imager (OLI) and sentinel-2 satellites. To achieve the objectives of the study many Water Index image-processing techniques used to delineate the water body boundary. The study shows that the Modified Normalized Difference Water Index (MNDWI) is most useful technique more than the Normalized Difference Water Index (NDWI), to delineate water surface from other land features.
\end{abstract}

Key Words: Landsat-8 OLI, sentinel-2, NDWI, MNDWI

Vol.(50); Iss.(6); No.(1); Jun.2021 ISSN 1110-0826 
Journal of Environmental Sciences (JES)

Institute of Environmental Studies and Research, Ain Shams University

El-Leithy. et al.

\section{INTRODUCTION}

High Aswan Dam Reservoir (HADR) (Lake Nasser) is a vast reservoir in southern Egypt, and northern Sudan. It is considered as one of the largest man-made lakes in the world. Strictly, "Lake Nasser" refers only to the much larger portion of the lake that is in Egyptian territory (83\% of the total volume), with the Sudanese preferring to call their smaller body of water "Lake Nubia".

Water scarcity in Egypt requires better management of water resources. The most important parameters needed for lake water management are the lake surface area and volume at any specific time. This study is focused on developing an innovative technique that enables the accurate calculation of the lake water surface area at any specific time using satellite images. The use of historical (archived) satellite images in the proposed approach is the critical data source to achieve the objectives. Additionally, recent satellite data from different satellites will be used.

Neal-real time and long-term water body monitoring is essential for the effective management and conservation of Lake Nasser as one of the most important water resources in Egypt, which is enormously benefited from the advent of remotely sensed images. However, an efficient as well as robust method to perform water detection from these images remains challenging due to the various noise sources from heterogeneous backgrounds. A robust methodology is designed in this study to extract free surface water from 
multi-temporal and multispectral images acquired by Landsat-8 OLI and sentinel-2 satellites.

This study aimed to: Enable accurate calculation of the lake surface using satellite images at any specific time, whenever a single satellite image for any part of the lake is acquired or water level information is obtained from the site gauges.

Calculate the lake surface with additional information like temperature, pressure, etc. which enable accurate estimates of evaporation from the reservoir.

\section{STUDY AREA}

Aswan High Dam Reservoir (AHDR) is formed as a result of the commission of Aswan High Dam (AHD). The reservoir is $500 \mathrm{~km}$ long with an average width of $12 \mathrm{~km}$, where $350 \mathrm{~km}$ is in Egypt and 150 is in Sudan. The reservoir is located between latitudes 21.8 to $24.0 \mathrm{~N}$ and longitudes 31.3 to $33.1 \mathrm{E}$. Its surface area is $6500 \mathrm{~km} 2$ at the maximum water level (i.e. $182 \mathrm{~m}$ upstream the dam), (Mosa, 2016).

It covers a total surface area of $6,500 \mathrm{~km}^{2}$ at water level of 182 , as shown in the following figures. 
Journal of Environmental Sciences (JES)

Institute of Environmental Studies and Research, Ain Shams University

El-Leithy. et al.

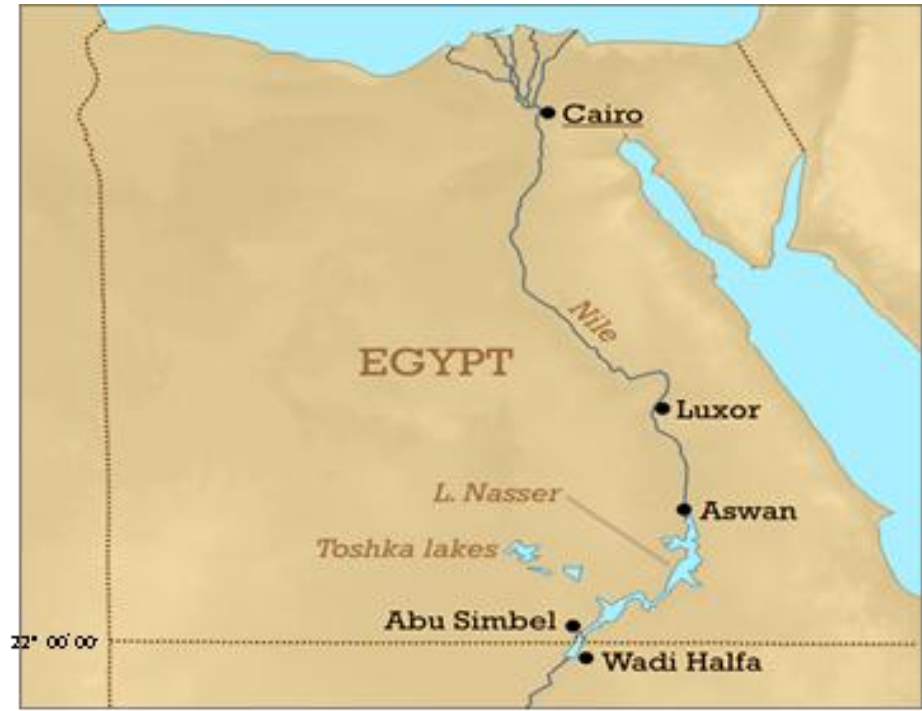

Figure(1): line map of Egypt showing Lake Nasser location

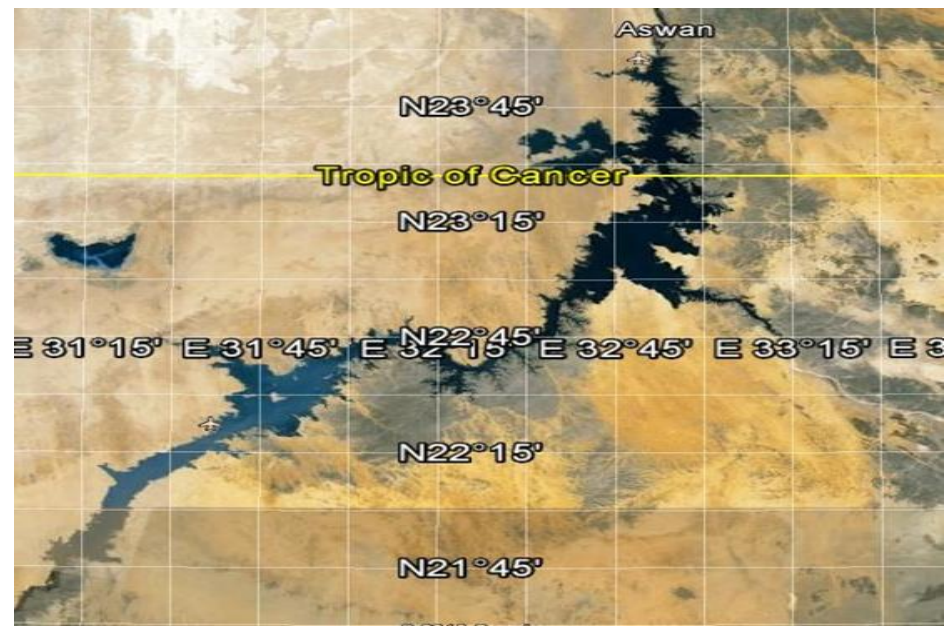

Figure(2): Satellite image showing the study area of Lake Nasser 


\section{PREVIOUS STUDIES}

To achieve the research objectives, references read to provide the required information.

- Independent threshold estimation methods are essential for optimized classification of Normalized Difference Water Index (NDWIs) given that indexes can generate distinct water maps for the same areas. The use of optimized thresholds revealed that indexes that combine the Near InfraRed (NIR) and green bands (NDWIG/NIR) are less efficient for detecting water bodies in arid areas, (Yang, 2015).

- NDWI thresholding method introduced for delineating surface water features and provided real examples of surface water mapping with the Landsat Thematic Mapper (TM) and the Moderate Resolution Imaging Spectroradiometer (MODIS) data, (Lei, 2004).

- Results showed that a DN-based threshold had significant dependence on the reflectance-based counterpart. temporal influences accounted for approximate $90 \%$ of the difference. The findings should be valuable for quantitative remote sensing and for improving the reliability of diverse long-term studies using multi-temporal images, (LIU, 2012).

- The OLI images can be accurately and easily used for land surface water mapping (LSWM). The NDWI model based on the green band (Band 3) and the SWIR1 band (Band 6) of the OLI is the best indicator or LSWM, (Zhiqiang, 2014). 
Journal of Environmental Sciences (JES)

Institute of Environmental Studies and Research, Ain Shams University

El-Leithy. et al.

\section{DATA ACQUISITION AND MANIPULATION}

The data required to achieve the objectives of the study are the satellite images and the lake water gauges level measurements.

1) Satellite Data Overview: The number of images required in this study is quite large as it is required to have information on lake body at different stages of the water level. It is planned to utilize primarily satellite images acquired from the Landsat satellites series as these satellites acquire images for the earth in regular basis (16 days temporal resolution). Other satellite images will be utilized as the proposed approach not based on single data type. High resolution images like Quickbird and Orbview can be limitedly utilized as they have limited coverage over the study area in addition to limited availability in free basis.

Regarding data availability, it is found that one of the huge sources of free Landsat images is the US Geological Survey (USGS) archiving site. The European Space Agency (ESA) avails their data sets to the users for research purposes.

2) Lansat-8 OLI Satellite Sensor System: The L8 mission objective is to provide timely, high-quality visible and infrared images of all landmass and near-coastal areas on the Earth, continually refreshing an existing Landsat database. Data input into the system are sufficiently consistent with currently archived data in terms of acquisition geometry, calibration, coverage, and spectral characteristics to allow for comparison of global and regional change detection and characterization. 


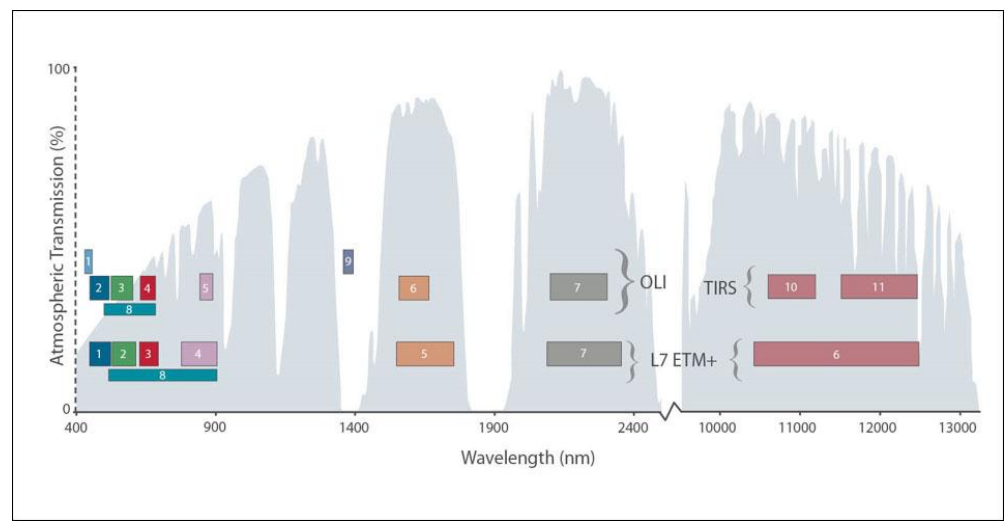

Figure(3): Landsat 8 Operational Land Imager (OLI) and Thermal Infrared Sensor (TIRS), spectral distribution

Landsat 8 Operational Land Imager (OLI) and Thermal Infrared Sensor (TIRS) images consist of nine spectral bands with a spatial resolution of 30 meters for Bands 1 to 7 and 9. New band 1 (ultra-blue) is useful for coastal and aerosol studies. New band 9 is useful for cirrus cloud detection. The resolution for Band 8 (panchromatic) is 15 meters. Thermal bands 10 and 11 are useful in providing more accurate surface temperatures and are collected at 100 meters. Approximate scene size is $170 \mathrm{~km}$ north-south by $183 \mathrm{~km}$ eastwest (106 mi by $114 \quad \mathrm{mi}), \quad$ (http://www.cesbio.ups-tlse.fr/ multitemp/?p=1774).

3) Sentinel-2 satellite Sensor system: Driver for Sentinel-2 Level-1B, Level$1 \mathrm{C}$ and Level-2A products. (GDAL $>=2.1$ ) 
The SENTINEL2 driver will be used if the main metadata .xml file at the root of a SENTINEL2 data product is opened (whose name is typically S2A_OPER_MTD_SAFL1C_....xml). It can also accept directly .zip files downloaded from the Sentinels Scientific Data Hub

To be able to read the imagery, GDAL must be configured with at least one of the JPEG2000 capable drivers.

SENTINEL-2 data are acquired on 13 spectral bands in the visible and near-infrared (VNIR) and Short-wavelength infrared (SWIR) spectrum, as show in the below table:

\begin{tabular}{|c|c|c|c|c|c|c|}
\hline & \multicolumn{3}{|c|}{$\begin{array}{l}\text { Landsat } 8 \text { Operational } \\
\text { Land Imager (OLI) }\end{array}$} & \multicolumn{3}{|c|}{ Sentinal-2 } \\
\hline & Bands & $\begin{array}{l}\text { Wave-length } \\
(\mu \mathrm{m})\end{array}$ & $\begin{array}{c}\text { Resolution } \\
\text { (meters) }\end{array}$ & Bands & Wave-length $(\mu \mathrm{m})$ & $\begin{array}{c}\text { Resolution } \\
\text { (meters) }\end{array}$ \\
\hline Coastal aerosol & B 1 & $0.43-0.45$ & 30 & N/A & N/A & N/A \\
\hline Blue & B 2 & $0.45-0.51$ & 30 & B02 & $.457-.522$ & 10 \\
\hline Green & B 3 & $0.53-0.59$ & 30 & в03 & $.542-.577$ & 10 \\
\hline Red & B4 & $0.64-0.67$ & 30 & B04 & $.65-.68$ & 10 \\
\hline Near Infrared & B 5 & $0.85-0.88$ & 30 & в08 & $.784-.90$ & 10 \\
\hline SWIR 1 & B 6 & $1.57-1.65$ & 30 & B11 & $1.57-1.66$ & 20 \\
\hline SWIR 2 & B 7 & $2.11-2.29$ & 30 & B12 & $2.10-2.28$ & 20 \\
\hline Panchromatic & B 8 & $0.50-0.68$ & 15 & N/A & N/A & N/A \\
\hline Cirrus & в 9 & $1.36-1.38$ & 30 & N/A & N/A & N/A \\
\hline Thermal Infrared-1 & В 10 & $10.60-11.19$ & $100 *(30)$ & N/A & N/A & N/A \\
\hline Thermal Infrared-2 & B 11 & $11.50-12.51$ & $100 *(30)$ & N/A & N/A & N/A \\
\hline
\end{tabular}

Figure (4): Comparison Table between Landsat and Sentinel-2 spectral bands

4) Water level measurements:

- HYDROWEB: The products offered by the Hydroweb project consist of continuous, long-duration time-series of the levels of large lakes with surface areas over $100 \mathrm{~km} 2$, reservoirs and the 20 biggest rivers in the world. 
Journal of Environmental Sciences (JES)

Institute of Environmental Studies and Research, Ain Shams University

El-Leithy, et al.

The operational measurement series are updated no later than 1.5 days after a new altimetry measurement becomes available. They cover about 80 large lakes and 300 measurement points along about 20 major rivers.

The research measurement series are updated at regular intervals according to the progress made with processing by the LEGOS laboratory. They cover about 150 large lakes and 1,000 measurement points along about 20 major rivers, (http://hydroweb.theia-land.fr/).

Continental waters account for only $0.65 \%$ of the total amount of water on Earth, $97 \%$ being stored in the oceans and $2.15 \%$ in the cryosphere. However, these waters have a significant impact on life on Earth and household needs. They also play a major role in climate variability. Water on Earth is continually recycled through precipitation, evaporation and run-off towards the sea. The increasingly accurate characterisation of the water cycle on land surfaces enables more accurate forecasting of the climate and more careful control of global water resources (human consumption and activities such as agriculture, urbanisation and the production of hydroelectric power, for example), (http://hydroweb.theia-land.fr/).

Satellite altimetry is used to measure the water level of rivers, lakes and flooded plains. Since the early 1990s, various altimetry satellites have been launched: ERS-1 (1991-1996), Topex/Poseidon (1992-2006), ERS-2 (19952011), GFO (2000- ), Jason-1 (2001-2013), Envisat (2002-2012), Jason-2 (2008- ) and Saral/Altika (2013- ). Their main goal is to measure sea surface height, but their altimetry measurements can also be used to measure the level 
Journal of Environmental Sciences (JES)

Institute of Environmental Studies and Research, Ain Shams University

El-Leithy. et al.

of continental waters (inland seas, rivers, lakes, wetlands and reservoirs), (http://hydroweb.theia-land.fr/).

\section{MATERIALS AND METHODS}

Spectral processing techniques of remotely sensed data are used to distinguish between different land features. In case of delineating the water surface from other land feature, the following technique is the very successful in discriminating between eater surface and surrounding.

1) Modified Water Index: In this method improvement is made to water index which uses the short infrared wave band (the fifth band of TM) to substitute the near infrared band to improve Normalized Difference Water Index, the equation is:

MNDWI $=($ GREEN-MIR $) /($ GREEN+MIR $)$

MNDWI is the abbreviation of Modified Water Index, GREEN is green band (the second band of TM). MIR is short infrared wave band (the fifth band of TM). Water has low reflectance in the fifth band of TM, thus using the fifth band to substitute the fourth band can highlight water information well. The principle is that water reflectance in green and red band is higher than that of near infrared band and short infrared wave band, after addition, reflectance of the second and the third band is higher than that of the fourth and the fifth band. It was found that the NDWI calculated from (green $\mathrm{SWIR}) /($ green $+\mathrm{SWIR})$, where SWIR is the shorter wavelength region (1.2 to $1.8 \mu \mathrm{m})$, has the most stable threshold. Accordingly, NDWI is recommended 
to be employed for mapping water, but adjustment of the threshold based on actual situations is necessary, (Lei Ji, Li Zhang, 2004).
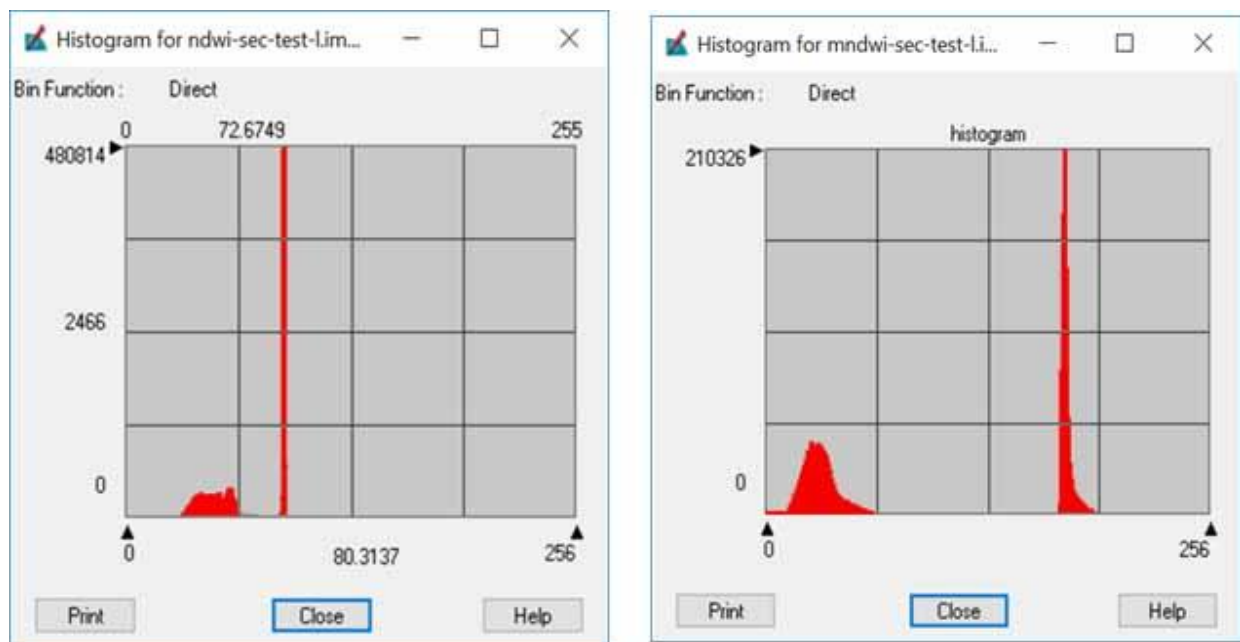

Figure (5): showing in the left NDWI image histogram, on the right the MNDWI image histogram

From the previous figure, it is very clear that the MNDWI is most technique to delineate water surface from other land features.

2) Methodology: The methodology followed in this research adopted satellite image processing techniques to achieve the objectives. To experiment the consistency using different satellite data sources, image acquired from Landsate-8 (6-3-2016) and sentienal-2 (7-3-2016) satellites is used for comparison purposes.

The image processing techniques and function used in this research carried out using the ERDAS IMAGINE software version 10. 


\section{- Dates processing sequence:}

1. Merge bands 1,2,3,4,5 corresponding to Green, Red, Near Infra-Red, Short Wave Infra-Red 1(SWIR 1) and Short Wave Infra-red-2 (SWIR 2)

2. Sentinel SWIR 1 resolution merge to 10 meters

3. Apply Modified Normalized Difference Water Index (MNDWI)

4. Water threshold level determination from MNDWI single band image

5. Recode MNDWI layer to binary layer (0 and 1)

6. MNDWI image primary clean-up (shadow slivers)

7. Mosaicking of MNDWI images, acquired at the same date

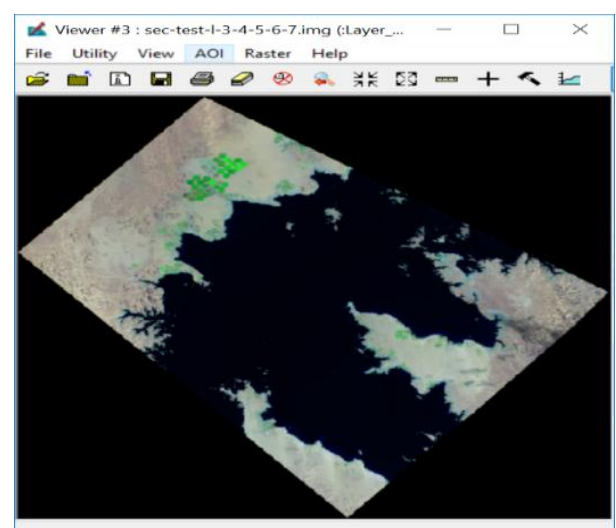

Figure(6): Landsat image (6/3/2016), bands:2,4,7 (B,G,R)

Test area: the following image boundary subtracted from both Landsat-8 and sentienal-2 images to apply all processing steps. 
Journal of Environmental Sciences (JES)

Institute of Environmental Studies and Research, Ain Shams University

El-Leithy, et al.

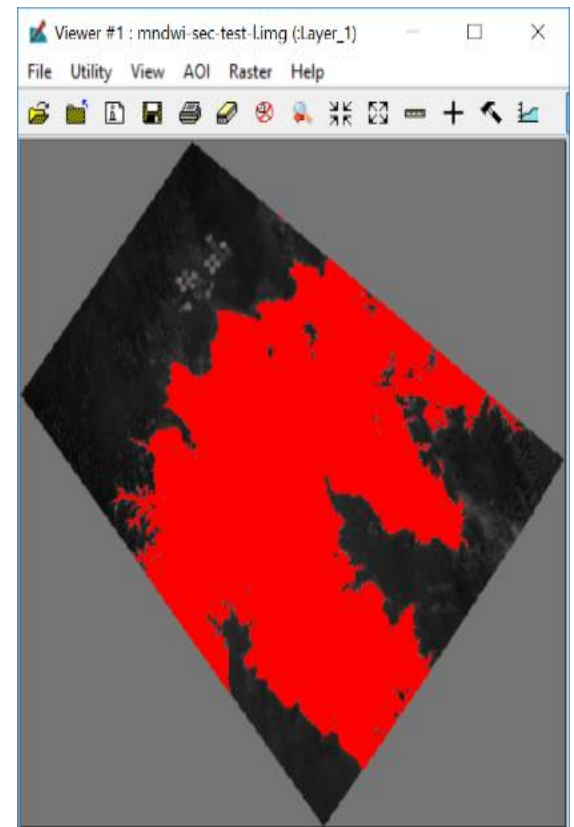

Figure (7): Red color showing levels above threshold, with clear separation between water and inland features

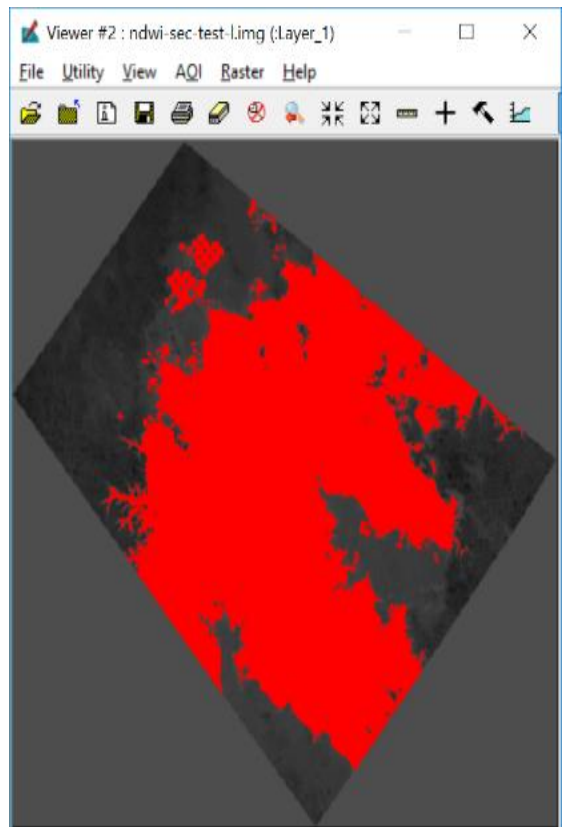

Figure(8): Red color showing levels above threshold, with interference between water and inland features

To achieve the upove result MNDWI applied to Landsat- 8 image. The resultant image data is streched to unsigened 8 bits to distrebute image data values from 0 to 255 . Histogram of the resultant image shows best value to discriminate between the water and other land features at level 118 .

- Recode : consequentely values from 0 to 118 is mapped to 0 value, where as values from 118 to 255 are mapped to 1 . 
- Edge detection 3X3: edge detection process is carried out to enhance the border delineating the water surface from other features. in this case spatial convolution filter with a box of $3 \times 3$ pixels is used.

- Raster to vector: the vector data set extracted from the raster image after applying the $3 \times 3$-convolution filter to the recoded image. RASTER TO ARC/INF COVERGE function in ERDAS IMAGINE under the vector module is applied.
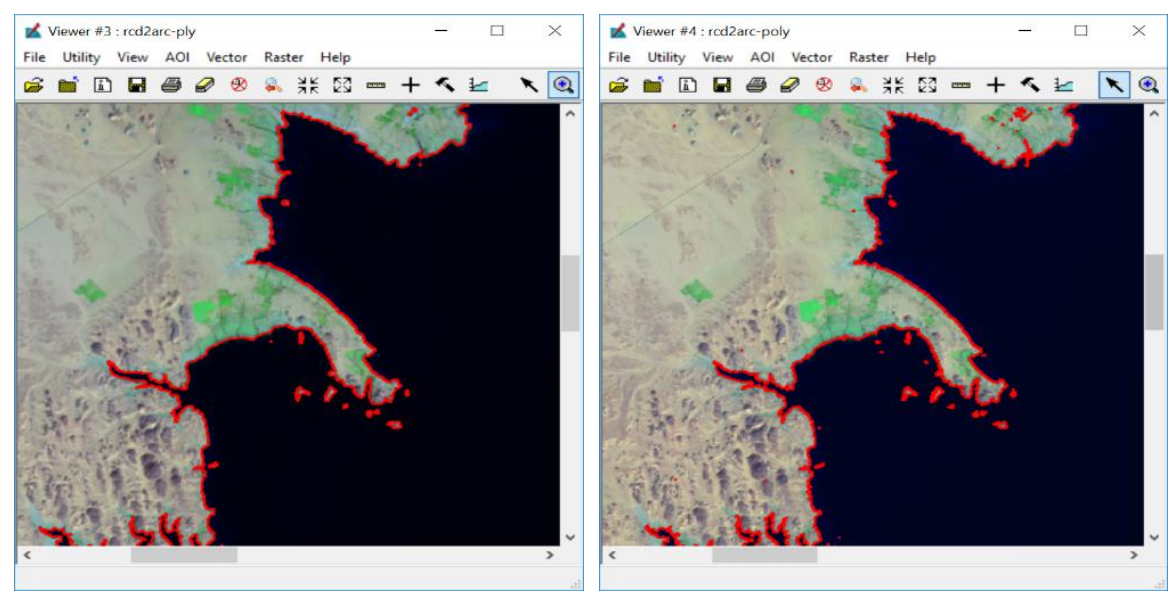

Figure (8): Landsat image (left) and Sentinel-2 image (right) with the vector data overplayed in red

- Lake Nasser water surface area: To achieve the objectives of the study, all previous steps applied to lansat-8 images acquired in 6-3-2016. The images cover the whole lake Nasser to enable the calculation of the complete water surface area. 
The resultant Landsat- 8 image (figure 10), after applying the required functions and techniques showed that the net lake Nasser water surface area at 15-1-2015 presented by 6,130,053 pixels with pixel resolution of 30x30 meter. Pixels count calculated using histogram statistics by ERDAS IMAGINE.

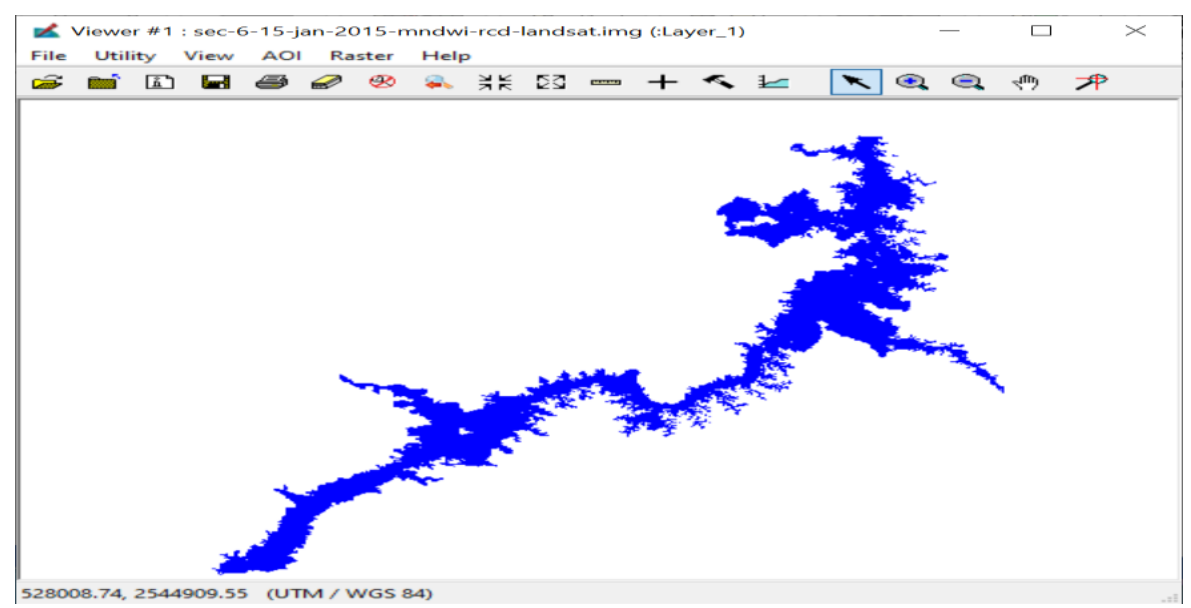

Figure (10): resultant Lake surface area, extracted from Landsat images

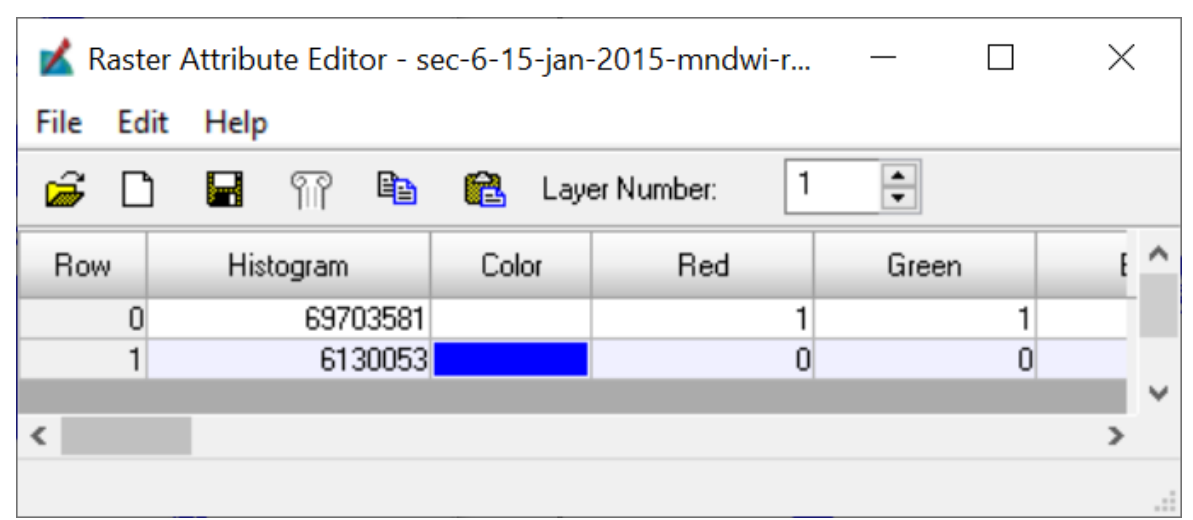

Figure (11): pixels count in resultant image, blue pixels present water surface

Vol.(50); Iss.(6); No.(1); Jun.2021 


\section{RESULTS}

The computed statistics, for the resultant image shows that the lake surface area presented by $6,130,053$ pixels with pixel resolution of 30x30 meter.

Therefore the net lake surface area $=6130053 * 30 * 30=5,517 \mathrm{~km}^{2}$

At this date, from HYDROWEB data, the lake surface height is 179.98 meters.

The resultant Landsat- 8 image after applying the required functions and techniques shows the net lake Nasser water surface area at 6-1-2015 is 5,517 $\mathrm{km}^{2}$ at surface level of 179.98 meters.

Surface area calculated by equation,

$$
\begin{gathered}
=55979.564-1763.753(\mathrm{WL})+20.777787(\mathrm{WL})^{2}- \\
0.1094812(\mathrm{WL})^{3}+0.00022164498(\mathrm{WL})^{4},
\end{gathered}
$$

\section{Gives the following result:}

Water level by the equation $=5,879.09 \mathrm{Km}^{2}$

Compared to $5,517 \mathrm{~km}^{2}$ calculated from the satellite image. The surface area difference $=362.1 \mathrm{Km}^{2}$, which represent $6.16 \%$.

\section{CONCLUSION AND RECOMMENDATION}

The study shows that the resultant lake surface area from Landsat- 8 harmonious with results calculated from the empirical equation.

The study also shows that remote sensing techniques by satellite images is a useful tool, and it can supersede, the future hydrographic survey. 
The MNDWI is most successful technique to delineate water surface from other land features.

The processing of Landsat- 8 and setienal- 2 satellite images for the purposes of this research, water surface delineation, shows very high degree of consistency for the scale up to 1:50,000.

Both types of data (Landsat-8 and setienal-2) shows very poor results if used with scale 1:25,000 and of course, the higher scale.

It is recommended to process multiple images from either landsat- 8 or Sentinel-2 in different dates representing different seasons, to compare and analysis the lake surface area with the used equation.

\section{REFERENCES}

Baup F., Frappart F., J. Maubant,( 2014): Use of satellite altimetry and imagery for monitoring the volume of small lakes, IEEE International, Geoscience and Remote Sensing Symposium (IGARSS): $157-160$.

Berry P.A.M., Smith R.G. \& Benveniste J.,(2012): Envisat Altimetry For River And Lakes Monitoring, IEEE International, Geoscience and Remote Sensing Symposium (IGARSS):1844-1847.

Campos J. C., Sillero N., Brito J. C.,(2012): Normalized difference water indexes have dissimilar performances in detecting seasonal and permanent water in the Sahara - Sahel transition zone, ELSEVIR, Journal of Hydrology 465: 438-446. 
Duana Z., Bastiaanssen W.G.M.,(2013): Estimating water volume variations in lakes and reservoirs from four operational satellite altimetry databases and satellite imagery data, ELSEVIR, Remote Sensing of Environment, 134:403-416.

http://en.wikipedia.org/wiki/Lake_Nasser, June 2021

http://hydroweb.theia-land.fr/, September 2020.

http://www.cesbio.ups-tlse.fr/ multitemp/?p=1774, July 2018.

https://sentinel.esa.int/web/ sentinel/technical-guides/ sentinel-2-msi/level-2a/ algorithm, January 2018.

Lei J., Zhang L., Wylie B., (2009): Analysis of Dynamic Thresholds for the Normalized Difference Water Index, Photogrammetric Engineering \& Remote Sensing 75(11):1307-1317.

LIU Y.,(2012): Why NDWI threshold varies in delineating water body from multitemporal images?, IEEE International, Geoscience and Remote Sensing Symposium (IGARSS):4375-4378.

Mosa A. M.: Dynamic operation rules of multi-purpose reservoir for better flood management, Alexandria Engineering Journal, 57(3):16651679( 2016)

Yang Y., Liu Y., Zhoua M., Zhang S., Zhan W., Sun C., Duan Y., (2015): Landsat 8 OLI image based terrestrial water extraction from heterogeneous backgrounds using a reflectance homogenization approach, ELSEVIR, Remote Sensing of Environment 171:pp. 14-32.

Zakharova E. A., Kouraev A. V., Rémy F., Zemtsov V. A., Kirpotin S. N.,: Seasonal variability of the Western Siberia wetlands from satellite radar, ELSEVIR, Journal of Hydrology 512: 366-378. (2014)

Zhiqiang D. Z., Wenbo L., Dongbo Z., Liqiao T., Feng L., Hailei W., Yuanmiao G., and Bingyu S.,(2014): Analysis of Landsat-8 OLI imagery for land surface water mapping, Taylor \& Francis, Remote Sensing Letters, Volume 5(7): 672-681. 
Journal of Environmental Sciences (JES)

Institute of Environmental Studies and Research, Ain Shams University

El-Leithy, et al.

Vol.(50); Iss.(6); No.(1); Jun.2021

ISSN 1110-0826 